drugs can be continued during breast feeding, the infant would have to be closely monitored in order to identify sedation, or anticholinergic and other side effects. Breast feeding under the supervision of relatives would be necessary, as the mother may not be in a position to care for her infant. In mothers where breast feeding is contraindicated because of homicidal risk, regular reassessment of this status and early reinstitution of feeding when the risk reduces would be beneficial. Thus, assessment of the problems on a case by case basis would be mandatory, and breast feeding should be encouraged in all mothers without the risk of infanticide, as the morbidity and mortality of artificially fed infants is unacceptably high in developing countries.

Behrman, R. E., Vaughan, V. C. \& Nelson, W. E. (1987) Feeding of infants. In Nelson Textbook of Paediatrics, l3th edition (eds R. E. Behrman, V. C. Vaughan \& W. E. Nelson), pp. 123-138. Philadelphia: W. B. Saunders Company.

INwOOD, D. G. (1989) Post partum psychotic disorders. In Comprehensive Textbook of Psychiatry, Sth edition, (eds H. I. Kaplan \& B. J. Sadock), pp. 852-858. Baltimore: Williams \& Wilkins.

Kumar, V., Kumar, L. \& Dwivedi, P. (1981) Morbidity related to feeding patterns in privileged urban and underprivileged rural infants. Indian Paediatrics, 18, 743-749.

MORTOLA, J. F. (1989) The use of psychotropic agents in pregnancy and lactation. Psychiatric Clinics of North America, 12, 69-87.

UNNI, J. C. \& RiCHARD, J. (1988) Growth and morbidity of breastfed and artificially fed infants in urban South Indian families. Journal of Tropical Paediatrics, 34, 179-181.

Department of Child Health

JAYASHREE RAMASETHI

Christian Medical College Hospital

Vellore 632004 India

Department of Psychiatry

Christian Medical College

Vellore 632002 India

K. S. JACOB

\section{Spousal allegations of incest during transient psychotic episodes}

SIR: The interesting case report of Remington \& Rosenblat (Journal, August 1991, 159, 287-288) draws attention to the necessity of thorough investigations of sexual abuse made while psychotic. The authors speculate as to the genesis of the content of the psychotic material. We would like to add two points based upon our recent experience of treating a 37-year-old woman who became acutely psychotic two months after childbirth. She accused her husband of infidelity and of sexually abusing her 11-year-old daughter by her first marriage. After five days, her psychotic symptoms resolved and she withdrew the allegations.
In the cases described by Drs Remington \& Rosenblat, the father was perceived as neglecting his parental responsibilities. The authors speculate as to the role of this perception and the associated anger in the psychotic material. In our patient, perceived neglect was not an issue but, as with the patients described, there was marital conflict. Diminishing sexual activity in the context of marital conflict may lead to fears about sexual desirability, and the mechanisms of denial and projection could lead to false allegations of infidelity and sexual abuse. In our patient, not only had pregnancy and childbirth interfered with sexual activity but also her husband's recent prostatectomy and vasectomy.

The authors rightly emphasise the importance of thoroughly investigating such allegations despite the presence of psychosis. Such investigations, however, must be carried out sensitively, as the effect of false allegations upon the accused and the alleged victim may be traumatic. In our case, once the allegations had been shown to be false and withdrawn, several interviews were necessary to allow the spouse and daughter to express their distress. In the management of false allegations of sexual abuse, consideration must be given to the effect of both the investigation and the allegations themselves.

N. Sisodia
C. Sullivan
L. Whitney

Department of Psychiatry

University Hospital

Nottingham

SIR: We were interested in the two Canadian cases reported by Remington \& Rosenblat (Journal, August 1991, 159, 287-288) in which false allegations of sexual abuse were made by patients with transient psychotic illness. These were apparently the clearest reported examples of such allegations arising directly from acute psychosis, and on recovery the patients withdrew their claims, so no action was taken to deal with the abuse. However, the consequences of such allegations can be far more serious than this. We report a British case in which protracted legal proceedings have resulted.

Case report. Mrs X, a 29-year-old mother, presented with a paranoid psychosis one month after the birth of her fourth child. Her two elder children lived respectively with their grandmother and father. All the children were by the same father. Mrs X had a recent history of two similar psychotic episodes, precipitated by stress, and on both occasions she had made a full recovery. There was no known family history of psychiatric disorder.

At the onset of the current episode she alleged that her common-law husband had sexually abused their 10-yearold daughter. The daughter, who lived with her, confirmed 